Polymer Journal Vol. 1, No. 6, pp 639-655 (1970)

\title{
High-Resolution NMR Study of Chlorinated Polyethylenes
}

\author{
Takanori Saito, Yukihiro Matsumura, and Shigeo Hayashi \\ Central Research Laboratory, Showa Denko Co., \\ 2-24-60, Tamagawa, Ohta-ku, Tokyo, Japan.
}

(Received May 11, 1970)

\begin{abstract}
High-resolution NMR spectra of chlorinated polyethylenes with various chlorine contents were measured on $o$-dichlorobenzene solutions at $c a .160^{\circ} \mathrm{C}$. The chemical shifts for the resonances associated with the distribution of chlorine atoms along the polymer chain were resolved by the triad or pentad units, and content of the chemical units was quantitatively obtained.

Chemical units containing geminal dichloride were observed when chlorine content approached $\mathrm{ca} .40 \mathrm{wt} \%$.

The structure of chlorinated polyethylenes in the region of chlorine content below 40 wt $\%$ is characteristic of the statistically random distribution of chlorine atoms along the polymer chain. Various methylenes and methynes in various proton environments were observed, but chemical units such as vinylidene chloride sequences were not observed in the chain.

It was found that a chlorination condition slightly affected the chlorine distribution, namely the solution chlorination increased vicinal-dichloride units rather than geminaldichloride units. However, the molecular weight of the parent polymer did not affect the chlorine distribution of chlorinated polyethylenes.

The sequence-length distribution of methylenes was also obtained and the contents of longer methylene sequences $\left(-\left(\mathrm{CH}_{2}\right)_{n^{-}}, n \geqq 5\right)$ were computed using the results of Frensdorff and Ekiner's theoretical treatment.

KEY WORDS Chlorinated Polyethylenes / High-Resolution NMR / Assignment / Chlorine Distribution / Methylene-Sequence Length / $\alpha$, $\omega$-Dichloroparaffins / Vinyl Chloride-Ethylene Copolymer / Hydrogenated Poly(Vinyl Chloride)/
\end{abstract}

The structure of chlorinated polyethylene (CPE) was studied first by Thomson, et al., ${ }^{1}$ by means of infrared spectroscopy.

The absorption peaks in the fundamental infrared region were interpreted qualitatively by Nambu, ${ }^{2}$ and a rather quantitative treatment using the absorption intensity of methylenebending mode was provided by Oswald, et al. ${ }^{3}$

However, none of these papers adequately described the distribution of chlorine atoms along the polymer chain, and geminal-dichloride units were not observed in infrared measurements.

Though one of the present authors reported on methylene-sequence distribution with a simple coupling model of methylene-rocking mode, the results were not satisfactory because of the difficulty in separating the overlapping peaks and estimating the extent of the absorption coefficient. ${ }^{4}$

An excellent theoretical treatment of the sequence distribution of substituted polymers has been provided by Frendsdorff, et al. ${ }^{5}$ with Markov transition probability. They computed the triad probability and the block-length distribution of methylenes in several cases.

Recently high-resolution NMR spectroscopy has been applied extensively to the characterization of some chlorine contained copolymers and chlorinated polymers except for CPE.

For instance, the monomer-sequence distribution and reactivity ratio of vinylidene chloride -vinyl chloride copolymers (VdC-VC) have been studied by Chujo, et al., ${ }^{6}$ McClanahan, et al.,${ }^{7}$ Johnsen, ${ }^{8}$ Enomoto, et al.,${ }^{9}$ Yamashita,${ }^{10}$ and so on. And those of vinylchloride-ethylene copolymers ( $\mathrm{VC}-\mathrm{Et}$ ) have been studied by Misono, et al. ${ }^{11}$ Schaefer, ${ }^{12}$ and Wilkes, et al. ${ }^{13}$ 
As for substituted polymers, the structure of chlorinated poly(vinyl chloride)(CIPVC) and chlorinated poly(butadiene)(CIPBD) have been studied by Sobajima, et al. ${ }^{14}$ Petersen and Rånby, ${ }^{15}$ and Tho, et al., ${ }^{16}$ have also studied the structure of CIPVC. Svegliado, et al. ${ }^{17}$ have in particular studied chlorine distribution of CIPVC and determined the sequence length of vicinaldichloride units. They revealed that vicinaldichloride sequences are predominantly formed in the CIPVC chain and chlorine distribution are affected by the chlorination condition. ${ }^{17}$

It should therefore be useful to apply such ready high-resolution NMR spectroscopy to study chlorine distribution along the CPE chain, and to determine various factors affecting the chlorine distribution such as chlorination conditions and the degree of polymerization of original polyethylene. However, we do not intend to discuss the geometrical isomers of the CPE chain in this paper.

The above objectives can be achieved by the assignment of various chemical shifts such as triads and polyads even if the influence of geometrical isomers on chemical shifts are not taken into account.

Since the influence is so small that the difference in chemical shift of methylene protons arising from the tacticity of PVC, which has been discussed by several authors, ${ }^{25}$ is ca. 0.20 $\mathrm{ppm}$ and the the difference arising from the geometrical isomers of $\mathrm{VdC}-\mathrm{VC}$ copolymer is $0.16 \mathrm{ppm},{ }^{9}$ it can resonably be ignored for the purpose of our study.

It was thus concluded that the main peak in the spectrum resulted from the chemical shift arising from methylene protons or methyne protons in the chemical units.

The chemical shifts were interpreted with the aid of the empirical method ${ }^{18}$ based on the simple additivity of chemical shifts in addition to deduction from published assignments for the NMR spectra of similar polymers to CPE.

We attempted to determine the average sequence length of unsubstituted methylenes, and also to calculate the sequence length of methylenes and its content in order to get details on longer methylene sequences $\left(-\left(\mathrm{CH}_{2}\right)_{n}{ }^{-}\right.$ $n \geqq 5$ ) which could not be determined exactly by NMR spectroscopy. We also endeavoured to obtain more information on chlorine distribution along the polymer chain.

\section{EXPERIMENTAL}

\section{Materials}

CPE samples having various chlorine contents were prepared by different methods.

A-series samples were prepared by chlorination in water suspension at $120^{\circ} \mathrm{C}$, and S-series samples were prepared by solution chlorination in tetrachloroethane at $120^{\circ} \mathrm{C}$. The parent polymer of these CPE was a high-density polyethylene (commercial name, Sholex ${ }^{\circledR}$ ).

CPE thus obtained is often a mixture of various chlorine contents, because the rate determining step of the chlorination reaction of polyethylene $(\mathrm{PE})$ is controlled by the diffusion process of chlorine and thus the chlorine-content distribution of CPE is occasionally affected by factors such as reaction temperature, mixing conditions, chlorine concentration, and so on. Some samples were fractionated through a column of Johns Manvile Celite 535 using mixed solvent of $o$-dichlorobenzene as a good solvent and butyl or ethyl cellosolve as a non solvent, at $122^{\circ} \mathrm{C}$ (observed boiling point of methyl cellosolve). Some underwent successive solvent extractions with a Soxhlet's extractor at the boiling point of the following solvents: carbon disulfide, acetone, chloroform, trichloroethylene, toluene, and monochlorobenzene. Fractionated samples obtained by the above methods were designated FC (column fractionation) and FE (solvent extraction). On the other hand, whole polymers for which chlorinecontent distribution was ascertained to be uniform by column fractionation, ${ }^{24}$ were designated $\mathrm{W}$ in Tables III, IV, and V.

Hydrogenated poly(vinyl chloride) (HPVC) containing $42.8 \mathrm{wt} \%$ and $47.7 \mathrm{wt} \%$ of chlorine were prepared by the method of Cotman. ${ }^{19}$

$\alpha, \omega$-Dichloroparaffins $\left(\mathrm{CH}_{2} \mathrm{Cl}\left(\mathrm{CH}_{2}\right)_{n} \mathrm{CH}_{2} \mathrm{Cl}\right)$ were obtained from $\mathrm{K} \& \mathrm{~K}$ Laboratories, Inc., U.S.A.

VC-Et copolymer was prepared with hydroperoxides and a trialkylboron as catalysts. ${ }^{11}$

\section{Experiment}

The NMR spectra of CPE, at a resonance 
frequency of $100 \mathrm{MHz}$, were measured on $c a$. $15-20(\mathrm{wt} / \mathrm{vol} \%)$ of $o$-dichlorobenzene solution at $120-160^{\circ} \mathrm{C}$, and those of HPVC or VC-Et copolymer were measured on $\mathrm{ca} .18(\mathrm{wt} / \mathrm{vol} \%)$ of $o$-dichlorobenzene solution at $113^{\circ} \mathrm{C}$ with hexamethyldisiloxane $(\tau=9.90 \mathrm{ppm})$ as an internal-field locking.

The spectra of $\alpha, \omega$-dichloroparaffins were measured at $28^{\circ} \mathrm{C}$ with tetramethylsilane as an internal-locking signal.

The chemical shifts were reported as $\tau$-values in this paper.

The intensity of spectral peaks were analyzed with the area under the peaks which was determined by the ordinary weighing method of recording paper where overlapped peaks were split into symmetrical triangles to match the observed spectral peaks.

The NMR instrument used in this study was a Japan Electron Optics Model JNM.4H-100 spectrometer.

Chemical analysis of chlorine contents was carried out by titration with $\mathrm{Hg}\left(\mathrm{NO}_{3}\right)_{2}$ solution after combustion in an oxygen combustion flask.

The intrinsic viscosities of the chlorinated polyethylenes were measured in 2-chloro-p-xylene solution at $135^{\circ} \mathrm{C}$.

\section{RESULTS AND DISCUSSION}

\section{Interpretation of Spectra and Assignments}

Thirteen discriminative peaks were observed in the NMR spectra of CPE as shown in Figures 1 and 2 and considerable chemical units of
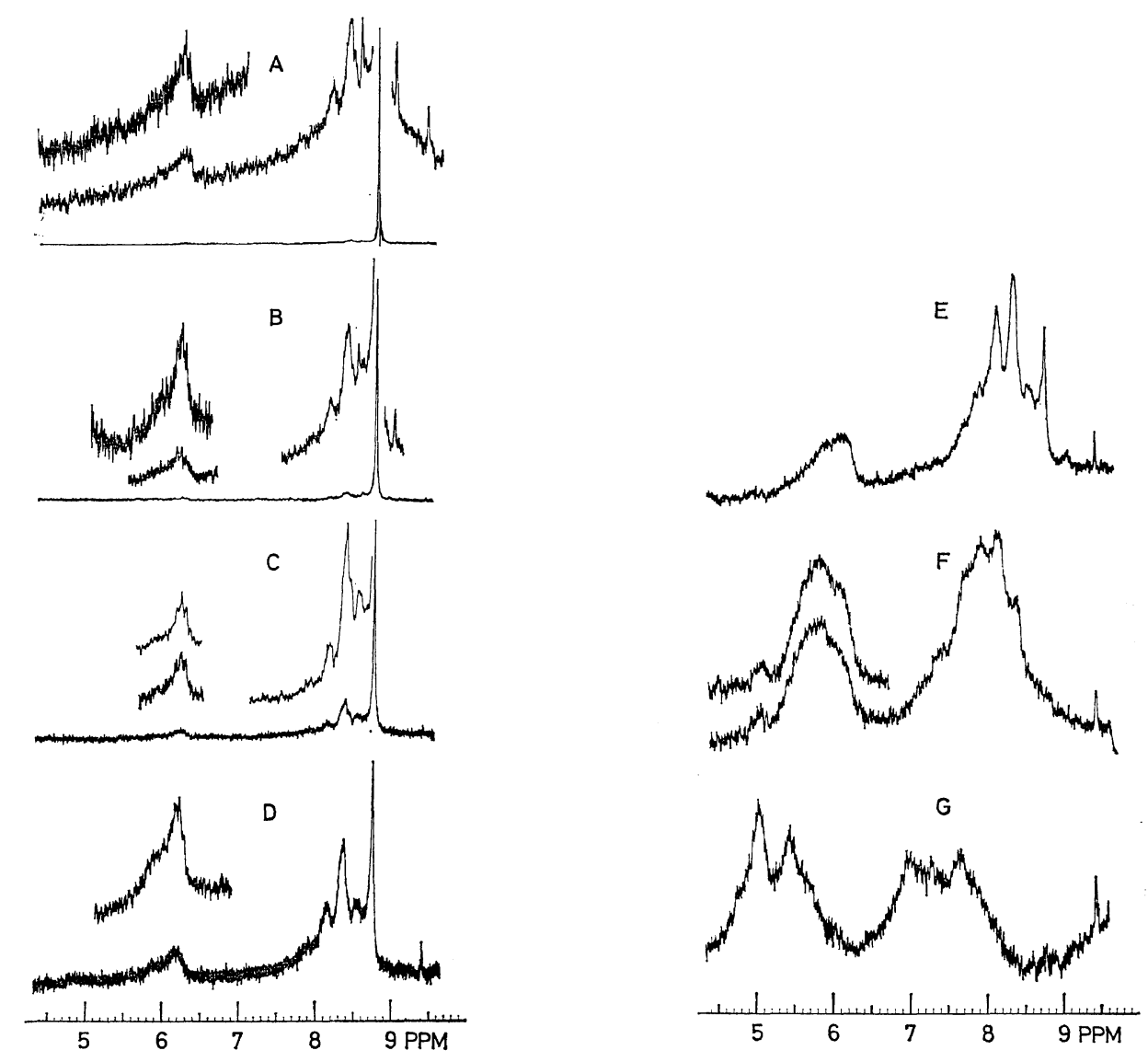

Figure 1. NMR spectra of CPE (suspension chlorination): (A) $16.6-\mathrm{Cl} \mathrm{wt} \%$; (B) $21.6-\mathrm{Cl}$ wt\%; (C) 32.7-Cl wt\%; (D) 41.3-Cl wt\%; (E) $50.7-\mathrm{Cl} \mathrm{wt} \%$; (F) $59.5-\mathrm{Cl} \mathrm{wt} \%$; (G) $70.2-\mathrm{Cl}$ $\mathrm{wt} \%$. 

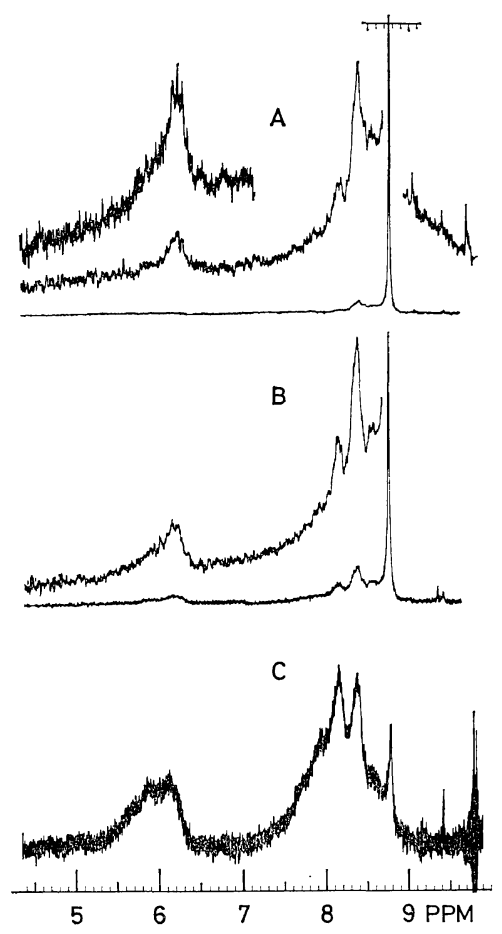

Figure 2. NMR spectra of CPE (solution chlorination): (A) 24.7-Cl wt \%; (B) 41.6-Cl wt \%; (C) 54.5$\mathrm{Cl}$ wt $\%$.

CPE will be represented generally as follows

$$
\begin{aligned}
& -(\mathrm{CH} \stackrel{*}{\mathrm{H}})_{i}-\left(\mathrm{CH}_{2}\right)_{l^{-}}-(\mathrm{CHCl})_{i}{ }^{\prime}-\left(\mathrm{CH}_{2}^{*}\right)_{m}-\left(\mathrm{CCl}_{2}\right)_{j^{-}} \\
& -\left(\mathrm{CH}_{2}\right)_{n}-\left(\mathrm{CCl}_{2}\right)_{j}{ }^{\prime}- \\
& \quad\left(i, i^{\prime}, j, j^{\prime}, l, m, n=0,1,2,3, \cdots\right)
\end{aligned}
$$

Thirteen peaks were considered as chemical shifts arising from the asterisked methylene or methyne protons in the above-described formula which exist in the various proton environments.

From the spectra of HPVC or VC-Et copolymer (Figure 3) and $\alpha, \omega$-dichloroparaffins (Figure 4), it was deduced that the chemical shift of methylene protons moved towards higher magnetic field with increasing methylene sequence length. Therefore the chemical shifts in the region of above $8.0 \mathrm{ppm}$ were attributed to chemical units such as $-(\mathrm{CHCl})-\left(\mathrm{CH}_{2}\right)_{l}-(\mathrm{CHCl})-$, $(l \geqq 2)$, and from the spectra of $\mathrm{VdC}-\mathrm{VC}$ copolymers ${ }^{7,16}$ or from the results of calculation by Enomsto, et al. ${ }^{9}$ The chemical shifts in the region of $6.0-8.0 \mathrm{ppm}$ were probably attributable to chemical units such as the asterisked

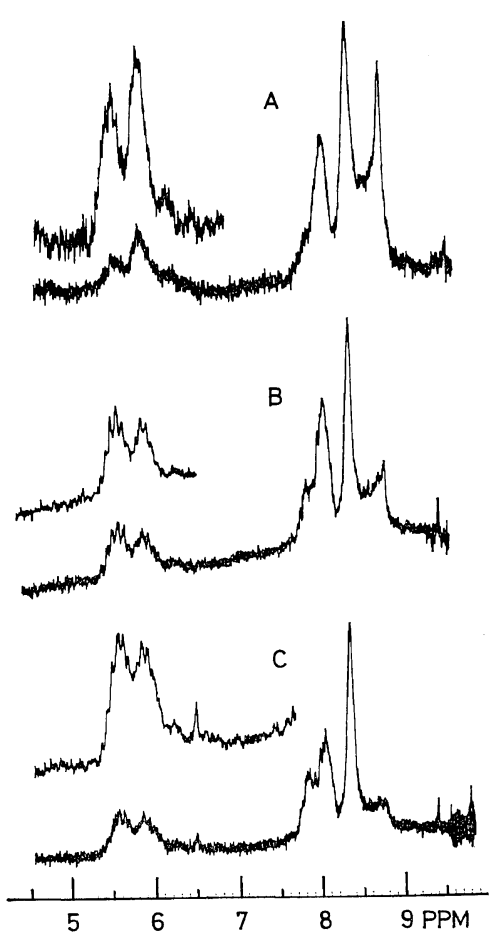

Figure 3. NMR spectra of HPVC and VC-Et copolymer: (A) HPVC 42.8-Cl wt \%; (B) HPVC 47.7-Cl wt\%; (C) VC-Et copolymer 50.4-Cl wt \%.

protons in the following structure.

$$
\begin{aligned}
& -(\mathrm{CHCl})_{i}-\left(\mathrm{CH}_{2}\right)-(\mathrm{CHCl})_{i}-\left(\mathrm{CH}_{2}^{*}\right)-\left(\mathrm{CCl}_{2}\right)_{j}-\left(\mathrm{CH}_{2}\right)^{*} \\
& -\left(\mathrm{CCl}_{2}\right)_{j}{ }^{\prime}{ }^{\prime}
\end{aligned}
$$

Chemical shifts of various types of methyne protons are expected to occur in the region below $6.0 \mathrm{ppm}$.

Accordingly, in the assignment of the chemical shifts of CPE, the NMR spectra may be divided into three regions of $\tau$-values which are named, for convenience, high magnetic fields (HMF region), middle magnetic fields (MMF region) and low magnetic fields (LMF region) which are defined as the region of chemical shift of $8.04-8.65 \mathrm{ppm}, 6.81-7.80 \mathrm{ppm}$, and $4.90-6.06$ ppm, respectively.

The notations $\mathrm{E}, \mathrm{V}$, and $\mathrm{D}$ are now introduced to represent concisely the chemical groups $\mathrm{CH}_{2}$, $\mathrm{CHCl}$, and $\mathrm{CCl}_{2}$ respectively.

HMF Region (8.04-8.65 ppm). In this region, four chemical shifts are observed at 8.65, 8.45, 8.27 , and $8.04 \mathrm{ppm}$. 
High-Resolution NMR Study of Chlorinated Polyethylenes

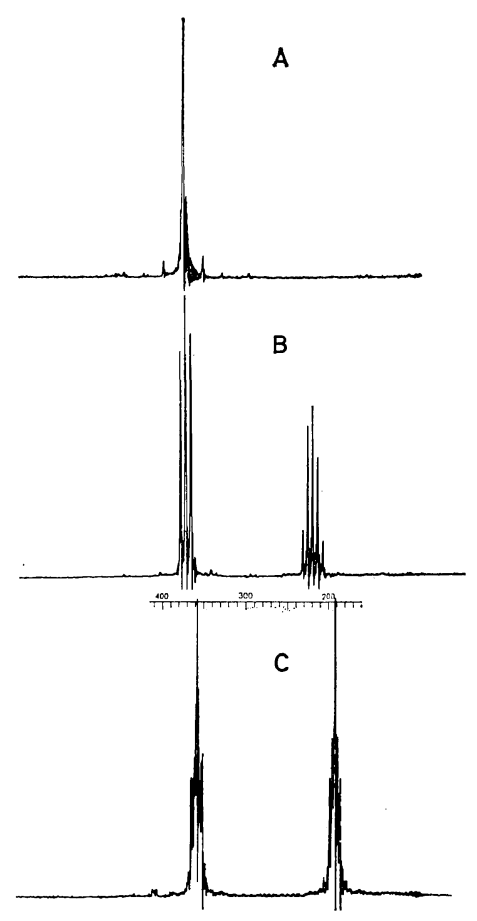

D

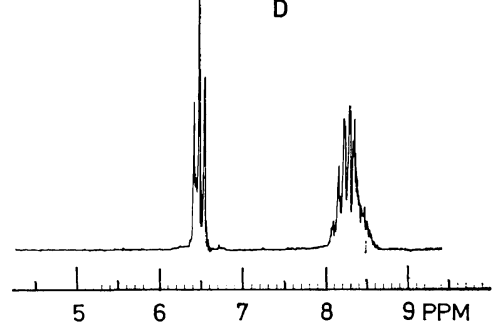

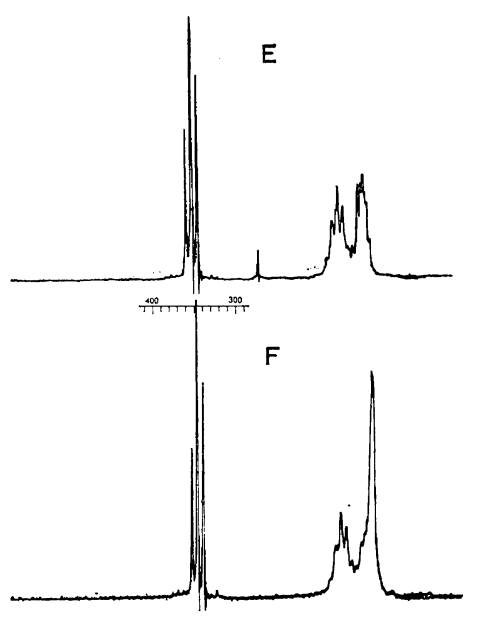
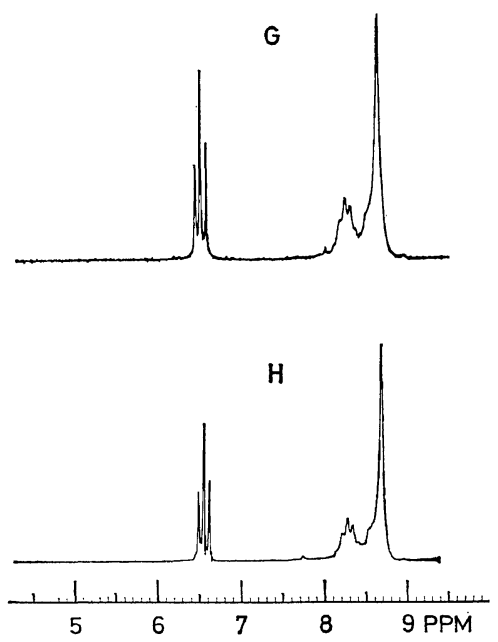

Figure 4. NMR spectra of $\alpha, \omega$-dichloroparaffins.
(A) 1,2-dichloroethane;
(B) 1,3-dichloropropane;
(C) 1,4-dichlorobutane
(D) 1,5-dichloropentane;
(E) 1,6-dichlorohexane;
(F) 1,8-dichlorooctane
(G) 1,9-dichlorononane;
(H) 1,10-dichlorodecane.

By analogy with the spectra of $\alpha, \omega$-dichloroparaffins (Figure 4), these chemical shift can be attributed to the asterisked methylene protons in the following polyad assignments.

$$
\begin{array}{cl}
\tau \text { ppm } & \multicolumn{2}{c}{\text { Assignment }} \\
8.65 & \text { VE }(\stackrel{*}{\mathrm{E}})_{n} \mathrm{EV} \quad(n \geqq 3) \\
8.45 & \text { VEEEEEV } \\
8.28 & \text { VEEE*V; } \quad \text { VE }(\mathrm{E})_{m} \stackrel{*}{\mathrm{E} V} \quad(m \geqq 2) \\
8.04 & \text { VE*EV }
\end{array}
$$

Strictly speaking, the chemical shift of the primed methylene protons in the VÉÉEV se- quence should be different from that of asterisked methylene protons in the VEEEV sequence. However from the spectra of 1,5-dichloropentane (Figure 4), it was deduced that the magnitude of the coupling constant between the primed and the asterisked methylene protons was almost equal to the difference in chemical shifts on the working frequency at $100 \mathrm{MHz}$.

Consequently, the chemical shift arising from both methylene protons of 1,5-dichloropentane will overlap each other. From a study of Figure 4, it was found that firstly the chemical shifts of the primed methylene protons in the 
T. Saito, Y. Matsumura, and S. Hayashi

$\mathrm{VE}\left(\mathrm{E}^{*}\right)_{m} \mathrm{E} \mathrm{V}(m \geqq 1)$ did not depend on methylenesequence length and these appeared at ca. 8.27 ppm, and secondly the chemical shifts of the primed and asterisked protons in the sequence of $\operatorname{VEE}(\stackrel{*}{\mathrm{E}})_{n} \mathrm{EEV}_{(n \geqq 1)}$ were almost equal at $8.65 \mathrm{ppm}$.

These estimates were ascertained from the NMR spectra of HPVC (Figure 3) which is expected to contain chiefly odd-number methylene sequences and a small amount of even-number methylene sequences arising from hydrogenation of head-to-head structures in the original PVC. The absence of chemical shift at $8.04 \mathrm{ppm}$ in the spectra of HPVC which is attributed to the VEEV structure is reasonable.

In the infrared spectra, rocking modes of methylene at $740 \mathrm{~cm}^{-1}$ and $730 \mathrm{~cm}^{-1}$ were observed, which were attributed to three and four methylene sequences; ${ }^{4}$ bending mode of methylene at $1455 \mathrm{~cm}^{-1}$ was also observed, which was attributed to methylene sequenees longer than nive. ${ }^{2,3}$ The existence of the three, four and more than five methylene sequences ascertained from infrared spectroscopy corresponded to the existence of chemical shifts at 8.27, 8.45, and $8.65 \mathrm{ppm}$, respectively.

The above-mentioned assignments were also ascertained from the NMR spectrum of VCEt copolymer, whose chemical shifrts were present at the same $\tau$-values in the spectra of HPVC, viz., 8.27, 8.45, and $8.67 \mathrm{ppm}$. It should be pointed out, however, that in our experiment the chemical shift arising from VEEEV was observed not at $8.35 \mathrm{ppm}^{11,13}$ but at $8.27 \mathrm{ppm}$. MMF Region (6.81-7.80 ppm). The chemical shifts of CPE were present in this region at $7.80,7.53,7.22$, and $6.81 \mathrm{ppm}$ and these chemical shifts were in close agreement with the chemical shifts of VdC-VC copolymer, ${ }^{16} \mathrm{CIPVC},{ }^{7,17}$ and PVC whose chemical shift of methylene proton appeared, as is well known, at $7.85 \mathrm{ppm}$.

The chemical shifts and assignments in the publisined papers are as follows

$\begin{array}{lllc}\tau \text { ppm } & \text { Assignment } & \text { Sample } & \text { Reference } \\ 7.85^{*} & \text { VEVEVEV } & \text { PVC } & 9 \\ 7.59 * * & \text { DEVËVED } & \text { VdC-VC } & 9 \\ 7.49 & \text { VVVËVED } & \text { CIPVC } & 17\end{array}$

$\begin{array}{lclr}7.18 & \text { VEVËDEV } & \text { VdC-VC } & 9 \\ 7.0 & \text { VËD } & \text { ClPVC } & 16 \\ 6.98 & \text { VVVËDEV } & \text { ClPVC } & 17 \\ 6.85 & \text { DEVËDED } & \text { VdC-VC } & 9 \\ 6.84 & \text { R-DE*VED } & \text { VdC-VC } & 7 \\ 6.52 & \text { VEDËDEV } & \text { VdC-VC } & 9\end{array}$

where $7.85 * \mathrm{ppm}$ is the mean value of the meso $(7.77 \mathrm{ppm})$ and racemic $(7.83 \mathrm{ppm})$ protons of $\mathrm{PVC}$, and $7.58^{* *} \mathrm{ppm}$ is that of meso $(7.51 \mathrm{ppm})$ and racemic $(7.67 \mathrm{ppm})$ protons of $\mathrm{VdC}-\mathrm{VC}$ copolymer. It is should be noted that the difference of the chemical shifts attributed to geometrical isomers is considered to be negligible in our paper.

Comparing the chemical shifts of CPE with those of similar polymers, assignments by triads for the chemical shifts of CPE are as follows

$\begin{array}{lc}\tau \text { ppm } & \text { Assignment } \\ 7.80 & \text { VËV } \\ 7.53 & \text { VËV } \\ 7.22 & \text { VËD } \\ 6.81 & \text { VËD }\end{array}$

The chemical shift of HPVC or VC-Et copolymer at $7.95 \mathrm{ppm}$ will be attributed to such chemical units as EEVEVEE.

It is suggested that chemical units such as VEDEDË in VdC-VC copolymer are not formed in the chain of CPE.

LMF Region (4.90-6.06 ppm). Chemical shifts of methyne protons among various types of sequences are expected to occur in this region and the chemical shifts of CPE appeared at $6.06,5.80,5.58,5.30$, and $4.90 \mathrm{ppm}$.

The chemical shifts at 6.06 and $5.80 \mathrm{ppm}$ of CPE are very close to that of DED in the poly (vinylidene chloride) chain at $6.14^{7}-6.18^{9} \mathrm{ppm}$ and these are also close to that of EVVेE in the CIPBD chain at 6.00 ppm. $^{14}$

However, both chemical shifts at 6.06 and $5.80 \mathrm{ppm}$ were observed in the spectra of slightly chlorinated PE (below $20 \mathrm{wt} \%$ of chlorine) as shown in Figure 1, and also in the spectra of HPVC as shown in Figure 3 and in the spectrum of $\mathrm{Et}-\mathrm{VC}$ copolymer $(72 \mathrm{~mol} \%$ of ethylene monomer). ${ }^{13}$ 
Above all, in the spectra of HPVC, it was shown that the intensity of the chemical shifts at $6.06 \mathrm{ppm}$ became stronger as the degree of hydrogenation increased.

These chemical shifts can be attributed not to DED or EVVE but to chemical units such as EVE surrounded by methylene sequences.

Therefore, in this paper the chemical shifts at 6.06 and $5.80 \mathrm{ppm}$ were assigned as follows

$$
\begin{array}{rrl}
\tau=6.06 & (\mathrm{E})_{n} \mathrm{EEVEE}(\mathrm{E})_{m} & (n, m \geqq 1) \\
\tau=5.80 & \operatorname{EEVE}(\mathrm{E})_{l} \mathrm{~V} & (l \geqq 0)
\end{array}
$$

and from published information

$$
\tau=5.58 \quad \text { VEV̌EV (PVC-like sequence) }
$$

The other chemical shifts of CPE at 5.30 and $4.90 \mathrm{ppm}$ were deduced from the interpretation

\begin{tabular}{|c|c|c|c|}
\hline$\tau$ & Assignment & Sample & Reference \\
\hline 5.43 & VV VैEV & ClPVC & 17 \\
\hline 5.36 & DEVED & $\mathrm{VdC}-\mathrm{VC}$ & 7 \\
\hline 5.32 & VEVED & ClPVC & 17 \\
\hline 5.09 & $\mathrm{~V} \stackrel{*}{\mathrm{~V}} \mathrm{~V}$ & ClPVC & 16 \\
\hline 4.95 & $\begin{array}{l}\mathrm{V}(\stackrel{*}{\mathrm{~V}})_{n} \mathrm{~V} \\
(n \geq 2)\end{array}$ & CIPVC & 17 \\
\hline
\end{tabular}
of the NMR spectra of VdC-VC copolymer or ClPVC.

In addition to the above interpretations the absorption peak centered near $5.30 \mathrm{ppm}$ was also observed in the NMR spectra of CIPBD and the intensity of this peak increased with the increase of chlorine content. ${ }^{14}$ The presence of an EVVE unit close to $\mathrm{V}$ or $\mathrm{D}$, therefore, was suggested by the spectrum of CIPBD.

The chemical shifts of CPE at 5.30 and 4.90 ppm were assigned as follows

$$
\begin{aligned}
& \tau=5.30 \quad \mathrm{EV} V \\
& \tau=4.90 \quad \text { V } \stackrel{*}{*} \text { Vै } V
\end{aligned}
$$

\section{Empirical Estimation of Chemical Shift}

It has been shown that chemical shift can be approximately calculated from the additivity of the component units. Published knowledge under this heading has been well summarized in the monograph by Emsley, et al. ${ }^{18}$

From their study, the $\tau$-value can be estimated from the following empirical relation

$$
\tau=T_{0}+\sum_{j} C_{j} T_{j}
$$

where $T_{0}=9.067$ and $T_{j}$ is the characteristic contribution of the chemical shift from the chemical group or feature, and $C_{j}$ is the number of times occurring in the molecule. This estimation was readily available for the determination of the pentad assignment. With their notations, empirical estimations are, for example, shown in Table I.

These estimations are not so different from

\begin{tabular}{|c|c|c|}
\hline \multirow{2}{*}{ Pentad } & \multicolumn{2}{|l|}{ Chemical shift $(\tau \mathrm{ppm})^{\mathrm{a}}$} \\
\hline & Calculation & Observed \\
\hline VVVैVV & $T_{0}+2 T_{1}+T_{25}+2 T_{2}+2 T_{26}+2 T_{27}=5.05$ & 4.90 \\
\hline DEVVE & $T_{0}+2 T_{1}+T_{25}+2 T_{2}+T_{26}+2 T_{27}=5.305$ & 5.30 \\
\hline VEV̈EV & $T_{0}+2 T_{1}+T_{25}+2 T_{2}+2 T_{27}=5.567$ & 5.50 \\
\hline EEVEV & $T_{0}+2 T_{1}+T_{25}+2 T_{2}+T_{27}=5.744$ & 5.80 \\
\hline (E) $\mathrm{EEV} \stackrel{\text { VE }}{\mathrm{E}}(\mathrm{E})$ & $T_{0}+2 T_{1}+T_{25}+2 T_{2}+2 T_{5}=5.921$ & 6.06 \\
\hline VVËDE & $T_{0}+2 T_{1}+3 T_{26}+2 T_{2}+T_{27}=7.144$ & 6.81 \\
\hline EVEDE & $T_{0}+2 T_{1}+3 T_{26}+2 T_{2}=7.321$ & 7.22 \\
\hline EVEVE & $T_{0}+2 T_{1}+2 T_{26}+2 T_{2}=7.575$ & 7.53 \\
\hline
\end{tabular}
the chemical shifts described in the previous section.

Eventually, thirteen chemical shifts were assigned by the triad or pentad sequences of

Table I. Estimation of chemical shift 
T. Saito, Y. Matsumura, and S. Hayashi

Table II. Chemical shift $(\tau)$ and assignment of CPE studied

\begin{tabular}{|c|c|c|c|c|c|}
\hline$\tau \mathrm{ppm}$ & Area & Triad & Pentad & Mol & $\%{ }^{\mathrm{a}}$ \\
\hline 8.65 & $S_{1}$ & & EEEEE & $a_{1}$ & \\
\hline 8.45 & $S_{2}$ & & (E)VEEEE $(\mathbf{V})^{\mathrm{b}}$ & $a_{2}$ & $2 a$ \\
\hline 8.27 & $S_{3}$ & & VËE*EV & $a_{3}$ & \\
\hline 8.04 & $S_{4}$ & & (E)EVËEV(E) & & $b$ \\
\hline 7.80 & $S_{5}$ & & (V)EVEVE(V) & $c_{1}$ & $1 \quad c$ \\
\hline 7.53 & $S_{6}$ & VEV & (D)EVEVE(D) & $c_{2}$ & \\
\hline 7.22 & $S_{7}$ & VËD & EVËDE & $d_{1}$ & $1 \quad d$ \\
\hline 6.81 & $S_{8}$ & VED & VVËDE & $d_{2}$ & \\
\hline 6.06 & $S_{9}$ & EV̆E & (E)EEVैEE(E) & $e_{1}$ & \\
\hline 5.80 & $S_{10}$ & EV̈E & EE ैैEE & $e_{2}$ & ${ }_{2} e$ \\
\hline 5.50 & $S_{11}$ & EVE & VEVEEV & $e_{3}$ & \\
\hline 5.30 & $S_{12}$ & $\mathrm{EVVV}^{*}$ & DEVVE & & $f$ \\
\hline 4.90 & $S_{13}$ & & VVVVV & & $g$ \\
\hline
\end{tabular}

a $a, b, g$ are mol\% of the asterisked methylenes or methynes in the pentad and $c, d, e, f$ are those in the triad.

b The chemical shifts of the primed methylenes in the $\operatorname{VE}^{\prime}(\mathbf{E})_{m}{ }^{\prime} \mathrm{V}(m \geqq 1)$ appear at $\tau=8.27$ ppm. $a_{2}$ is total mol\% of the asterisked and primed methylenes in the pentad.

considerable chemical units in the polymer chain. These assignments are listed in Table II.

\section{Quantitative Analysis}

Based on the above assignments, the contents of each chemical unit can be calculated as a content of asterisked units $\stackrel{*}{E}$ or $\stackrel{*}{V}$ from the following simultaneous equations, if the assignments are correct and the area ratio under the chemical shift of methylene proton to methyne proton is equal to 2 (in the case of $\mathrm{PVC}$, this ratio was reported by $\mathrm{McClahahan}^{7}$ as 2/0.9-2/ $0.95>2$ )

$$
\begin{aligned}
b / a & =S_{4} / 2 S_{a} \\
c_{1} / a & =S_{5} / 2 S_{a} \\
c_{2} / a & =S_{6} / 2 S_{a} \\
d_{1} / a & =S_{7} / 2 S_{a} \\
d_{2} / a & =S_{8} / 2 S_{a} \\
e_{1} / a & =S_{9} / S_{a} \\
e_{2} / a & =S_{10} / S_{a}
\end{aligned}
$$

$$
\begin{aligned}
e_{3} / a & =S_{11} / S_{a} \\
f / a & =S_{12} / S_{a} \\
g / a & =S_{13} / S_{a} \\
c & =c_{1}+c_{2} \\
d & =d_{1}+d_{2} \\
e & =e_{1}+e_{2}+e_{3}
\end{aligned}
$$

where, $S_{i}$ is the area under the chemical shift and $a, b, g$ are mol $\%$ of the methylenes or methynes in the pentads and $c, d, e, f$ are those in the triads as listed in Table II. $S_{a}$ has the following meaning

$$
S_{a}=\left(S_{1}+S_{2}+S_{3}\right) / 2
$$

The mol $\%$ of $\mathrm{CH}_{2}, \mathrm{CHCl}$ and $\mathrm{CCl}_{2}$ units can now be obtained from the assignments as follows

$$
\begin{aligned}
& E_{1}=a+b+c+d \\
& V_{1}=e+f+g \\
& D_{1}=d / 2
\end{aligned}
$$

In eq 17 the possibility of double counting for $\mathrm{CCl}_{2}$ units in the triad was considered. Total mol $\%$ of these units was normalized to $100 \%$ as follows

$$
\begin{aligned}
& E_{1}+V_{1}+D_{1} \\
= & a+b+c+d+e+f+g+d / 2=100
\end{aligned}
$$

Taking into account the peak area ratio of the chemical shift of 1,6-dichlorohexane $\left(S_{\tau=8.55}\right.$ : $\left.S_{\tau=8.27}=1.0: 1.07\right)$ and ignoring the peak area of $S_{\tau=8.27}$ in the spectra of 1,8-dichlorooctane, 1, 9-dichlorononane and 1,10-dichlorodecane $\left(S_{\tau=8.65}: S_{\tau=8.55}: S_{\tau=8.27}=1.0: 0.2: 0.5\right)$ the mole percent of methylenes in sequences longer than two methylenes can be calculated tentatively from the following relations

$$
\begin{aligned}
a & =a_{1}+a_{2}+a_{3} \\
a_{1} & =K(1+\alpha) S_{1} \\
a_{2} & =K\left\{(1+\beta) S_{2}-\alpha S_{1}\right\} \\
a_{3} & =K\left(S_{3}-\beta S_{2}\right) \\
K & =a /\left(S_{1}+S_{2}+S_{3}\right)
\end{aligned}
$$

where, $a_{1}, a_{3}$ are total mol $\%$ of asterisked methylenes and $a_{2}$ represents total mol $\%$ of asterisked and primed methylenes in the pentad 
as shown in Table II. $K$ is a normalizing factor.

In these equations, $\alpha$ and $\beta$ are, so to speak, splitting parameters of overlapping peaks and $\alpha=0.2, \quad \beta=1.0$ were assumed by estimation from the peak area ratio of the model compounds described above. The validity of this assumption is in question and is discussed in the following section.

From the calculated value of $a_{1}, a_{2}, a_{3}$, and $b$, the content of the triad $\operatorname{EEE}^{*}\left(a_{t}\right)$ and VEE $b(t)$ can be obtained as follows

$$
\begin{aligned}
& a_{\mathrm{t}}=a_{1}+a_{2} / 2+a_{3} / 3 \\
& b_{\iota}=b+a_{2} / 2+2 a_{3} / 3
\end{aligned}
$$

Whereas the sequence number of $\mathrm{V}$ in the pentad (V $\left.\stackrel{*}{\mathrm{~V}}{ }^{*} \mathrm{~V}\right)$ is unknown. The content of the triad VVE $\left(f_{\mathrm{t}}\right)$ and V ${ }^{*} \mathrm{~V}\left(g_{\mathrm{t}}\right)$ can then be determined, for instance, as follows

$$
\begin{aligned}
f_{\mathrm{t}} & =f+g / 5 \\
g_{\mathrm{t}} & =4 g / 5
\end{aligned}
$$

where it is assumed that at least one end of the pentad $\mathrm{VV}^{*} \mathrm{~V}^{*} \mathrm{~V}$ is close to the unit E.

The chlorine content, $X_{\mathrm{N}}$ (wt $\%$ of chlorine), is determined as follows

$$
\begin{aligned}
X_{\mathrm{N}}= & 100\left(35.5 V_{1}+71.0 D_{1}\right) / \\
& \left(14.0 E_{1}+48.5 V_{1}+83.0 D_{1}\right)
\end{aligned}
$$

The difference between $X_{\mathrm{N}}$ and the chlorine content from the chemical analysis $\left(X_{\mathrm{C}}\right)$ was quite small not only for CPE but also for HPVC and VC-Et copolymer.

Quantitative results are summarized in Tables III, IV, and V and are depicted in Figures 5 and 6.

Molecular weight of CPE was expressed relatively by intrinsic viscosity for some samples of nearly equal chlorine content, as listed in Table VI. However, significant differences in

\begin{tabular}{|c|c|c|c|c|c|c|c|c|c|}
\hline \multirow{2}{*}{ Samples } & \multicolumn{2}{|c|}{$\mathrm{Cl}$ wt $\%$} & \multicolumn{2}{|c|}{ Pentad } & \multicolumn{4}{|c|}{ Triad } & \multirow{2}{*}{$\frac{\text { Pentad }}{g}$} \\
\hline & $X_{\mathrm{c}}$ & $X_{\mathrm{N}}$ & $a$ & $b$ & $c$ & $d$ & $e$ & $f$ & \\
\hline A1FE & 16.6 & 17.6 & 84.3 & 4.8 & 2.6 & 0.0 & 8.4 & 0.0 & 0.0 \\
\hline A2FE & 17.6 & 19.9 & 83.9 & 4.7 & 1.7 & 0.0 & 9.8 & 0.0 & 0.0 \\
\hline A3FE & 21.6 & 18.4 & 84.1 & 5.2 & 1.9 & 0.0 & 8.8 & 0.0 & 0.0 \\
\hline $\mathrm{A} 4 \mathrm{~W}$ & 24.4 & 24.6 & 75.4 & 6.1 & 5.7 & 0.0 & 12.8 & 0.0 & 0.0 \\
\hline A5FC & 31.1 & 31.0 & 67.0 & 10.1 & 5.4 & 0.0 & 17.5 & 0.0 & 0.0 \\
\hline A6W & 32.7 & 31.8 & 67.5 & 7.3 & 7.2 & 0.0 & 18.1 & 0.0 & 0.0 \\
\hline A7W & 34.0 & 29.9 & 69.2 & 7.1 & 7.1 & 0.0 & 16.6 & 0.0 & 0.0 \\
\hline $\mathrm{A} 8 \mathrm{FC}$ & 41.0 & 38.0 & 53.1 & 14.0 & 9.1 & 0.0 & 23.7 & 0.0 & 0.0 \\
\hline A9W & 41.3 & 36.0 & 54.2 & 12.2 & 11.8 & 0.0 & 21.8 & 0.0 & 0.0 \\
\hline A10W & 43.2 & 38.0 & 50.6 & 12.6 & 12.1 & 1.9 & 21.8 & 0.0 & 0.0 \\
\hline A11FE & 50.7 & 48.4 & 30.0 & 16.6 & 15.2 & 4.4 & 30.2 & 1.5 & 0.0 \\
\hline $\mathrm{A} 12 \mathrm{~W}$ & 52.2 & 49.6 & 28.3 & 14.8 & 16.3 & 5.9 & 28.2 & 2.7 & 0.0 \\
\hline A13FE & 59.5 & 57.8 & 9.1 & 11.4 & 23.1 & 8.6 & 33.2 & 7.1 & 3.2 \\
\hline A14FE & 66.8 & 64.2 & 4.0 & 6.4 & 15.1 & 14.2 & 22.2 & 14.2 & 16.8 \\
\hline A15FE & 70.2 & 67.4 & 1.0 & 1.6 & 12.0 & 16.8 & 14.9 & 17.0 & 28.4 \\
\hline S1W & 24.7 & 22.2 & 79.4 & 5.2 & 4.3 & 0.0 & 11.2 & 0.0 & 0.0 \\
\hline S2W & 33.8 & 32.1 & 64.6 & 9.1 & 8.0 & 0.0 & 18.4 & 0.0 & 0.0 \\
\hline S3W & 34.7 & 31.6 & 62.9 & 10.6 & 8.6 & 0.0 & 17.9 & 0.0 & 0.0 \\
\hline $\mathrm{S} 4 \mathrm{~W}$ & 41.6 & 39.9 & 53.2 & 10.9 & 10.3 & 0.0 & 25.7 & 0.0 & 0.0 \\
\hline S5W & 54.5 & 53.4 & 22.5 & 14.5 & 17.9 & 2.7 & 35.8 & 2.7 & 2.7 \\
\hline HPVC1 & 42.8 & 42.0 & 50.2 & 0.0 & 21.9 & 0.0 & 28.0 & 0.0 & 0.0 \\
\hline HPVC2 & 47.7 & 48.5 & 34.3 & 0.0 & 29.5 & 0.0 & 36.2 & 0.0 & 0.0 \\
\hline VC-Et & 50.4 & 50.3 & 33.0 & 0.0 & 28.2 & 0.0 & 38.9 & 0.0 & 0.0 \\
\hline
\end{tabular}
various triad-contents were not observed among those samples.

Thus it can be pointed out that the distribution of chlorine atoms along the chain has

Table III. Mol\% of the asterisked methylenes or methynes in the triads or pentads 
T. Saito, Y. Matsumura, and S. Hayashi

Table IV. Mol $\%$ of triad or pentad as a content of the asterisked methylene or methyne

\begin{tabular}{|c|c|c|c|c|c|c|c|c|c|c|}
\hline Samples & $a_{1}$ & $a_{2}$ & $a_{3}$ & $c_{1}$ & $c_{2}$ & $d_{1}$ & $d_{2}$ & $e_{1}$ & $e_{2}$ & $e_{3}$ \\
\hline $\mathrm{A} 1 \mathrm{FE}^{\mathrm{a}}$ & 80.8 & 1.6 & 1.9 & 2.6 & 0.0 & 0.0 & 0.0 & 4.8 & 3.6 & 0.0 \\
\hline $\mathrm{A} 2 \mathrm{FE}^{\mathrm{a}}$ & 78.0 & 3.1 & 2.9 & 1.7 & 0.0 & 0.0 & 0.0 & 6.8 & 3.0 & 0.0 \\
\hline $\mathrm{A} 3 \mathrm{FE}$ & 79.2 & 2.9 & 2.0 & 1.9 & 0.0 & 0.0 & 0.0 & 6.1 & 2.7 & 0.0 \\
\hline $\mathrm{A} 4 \mathrm{~W}$ & 66.5 & 6.4 & 2.4 & 5.7 & 0.0 & 0.0 & 0.0 & 6.6 & 6.2 & 0.0 \\
\hline A5FC & 39.9 & 20.7 & 6.4 & 5.4 & 0.0 & 0.0 & 0.0 & 11.6 & 5.9 & 0.0 \\
\hline A6W & 43.3 & 16.1 & 8.1 & 4.7 & 2.5 & 0.0 & 0.0 & 12.5 & 5.6 & 0.0 \\
\hline A7W & 44.2 & 18.0 & 6.9 & 4.8 & 2.2 & 0.0 & 0.0 & 10.7 & 5.9 & 0.0 \\
\hline A8FC & 21.5 & 25.2 & 6.5 & 6.3 & 2.8 & 0.0 & 0.0 & 13.4 & 10.4 & 0.0 \\
\hline A9W & 19.4 & 26.7 & 8.1 & 7.7 & 4.1 & 0.0 & 0.0 & 13.3 & 8.6 & 0.0 \\
\hline A10W & 21.1 & 23.2 & 6.4 & 7.3 & 4.9 & 1.9 & 0.0 & 12.9 & 6.4 & 2.6 \\
\hline A11FE & 6.4 & 16.6 & 7.0 & 8.7 & 6.5 & 2.2 & 2.2 & 13.3 & 10.6 & 6.3 \\
\hline A12W & 5.2 & 15.8 & 7.3 & 9.4 & 6.9 & 3.2 & 2.7 & 12.5 & 10.5 & 6.2 \\
\hline A13FE & 1.1 & 5.7 & 2.2 & 12.7 & 10.4 & 6.2 & 2.4 & 8.9 & 14.2 & 10.1 \\
\hline $\mathrm{A} 14 \mathrm{FE}$ & 0.6 & 0.9 & 2.5 & 6.8 & 8.4 & 7.1 & 7.2 & 4.6 & 4.9 & 12.7 \\
\hline $\mathrm{A} 15 \mathrm{FE}$ & 0.4 & 0.4 & 0.2 & 3.1 & 8.8 & 6.6 & 10.2 & 3.9 & 4.4 & 6.6 \\
\hline S1W & 68.7 & 8.4 & 2.3 & 3.0 & 1.3 & 0.0 & 0.0 & 7.8 & 3.4 & 0.0 \\
\hline S2W & 34.8 & 25.5 & 4.3 & 5.4 & 2.6 & 0.0 & 0.0 & 11.1 & 7.3 & 0.0 \\
\hline S3W & 39.5 & 22.0 & 4.7 & 4.7 & 3.9 & 0.0 & 0.0 & 17.9 & 5.6 & 0.0 \\
\hline S4W & 29.4 & 16.4 & 7.4 & 7.2 & 3.1 & 0.0 & 0.0 & 14.4 & 11.3 & 0.0 \\
\hline S5W & 4.8 & 7.9 & 9.8 & 12.7 & 5.2 & 2.7 & 0.0 & 17.6 & 11.2 & 7.1 \\
\hline HPVC1 & 20.0 & 17.9 & 12.3 & 4.3 & $17.5^{\mathrm{b}}$ & 0.0 & 0.0 & 5.5 & 13.1 & 9.4 \\
\hline HPVC2 & 7.7 & 10.5 & 16.1 & 8.2 & $21.4^{b}$ & 0.0 & 0.0 & 3.7 & 14.3 & 18.2 \\
\hline $\mathrm{VC}-\mathrm{Et}$ & 6.7 & 6.7 & 19.6 & 10.7 & $17.4^{b}$ & 0.0 & 0.0 & 3.1 & 14.6 & 21.1 \\
\hline
\end{tabular}

Table V. Mol $\%$ of $\mathrm{CH}_{2}, \mathrm{CHCl}$ and $\mathrm{CCl}_{2}$ units

\begin{tabular}{lrrl}
\hline Samples & $E_{1}$ & $V_{1}$ & $D_{1}$ \\
\hline A1FE & 91.6 & 8.4 & 0.0 \\
A2FE & 90.3 & 9.8 & 0.0 \\
A3FE & 91.2 & 8.8 & 0.0 \\
A4W & 87.2 & 12.8 & 0.0 \\
A5FC & 82.5 & 17.5 & 0.0 \\
A6W & 81.9 & 18.1 & 0.0 \\
A7W & 83.4 & 16.6 & 0.0 \\
A8FC & 76.3 & 23.7 & 0.0 \\
A9W & 78.2 & 21.8 & 0.0 \\
A10W & 77.2 & 21.8 & 1.0 \\
A11FE & 66.1 & 31.7 & 2.2 \\
A12W & 65.2 & 31.8 & 3.0 \\
A13FE & 52.3 & 43.5 & 4.3 \\
A14FE & 39.8 & 53.1 & 7.1 \\
A15FE & 31.3 & 60.2 & 8.4 \\
S1W & 88.8 & 11.2 & 0.0 \\
S2W & 81.6 & 18.4 & 0.0 \\
S3W & 82.1 & 17.9 & 0.0 \\
S4W & 74.4 & 25.7 & 0.0 \\
S5W & 57.5 & 41.1 & 1.4 \\
HPVC1 & 72.0 & 28.0 & 0.0 \\
HPVC2 & 63.8 & 36.2 & 0.0 \\
VC-Et & 61.2 & 38.9 & 0.0 \\
\hline
\end{tabular}

little to do with the degree of polymerization of the skeletal chain.

Chlorination conditions were noted to have had some effect on the distribution of chlorine atoms along the polymer chain, and these are described in the next section.

\section{Selectivity and Mechanism of Chlorination}

The mole percent of total $\mathrm{CH}_{2}$ and $\mathrm{CHCl}$ units in the region of chlorine contents $\left(X_{0} \leqq\right.$ $40 \mathrm{wt} \%$ ) were substantially in close agreement with the results of completely random substitution computed by Frensdorff and Ekiner, ${ }^{5}$ as shown in Figure 5. VEV units were observed even in a CPE whose chlorine content was below $20 \mathrm{wt} \%$ of chlorine (average length of methylene $\bar{N}=8-10$ ) as shown in Table III or in Figures 6 and 7.

This fact reveals that any methylenes are substituted by chlorine atoms with almost equal probability, since the chlorination reaction of polyethylene appears to occur randomly in the 
High-Resolution NMR Study of Chlorinated Polyethylenes

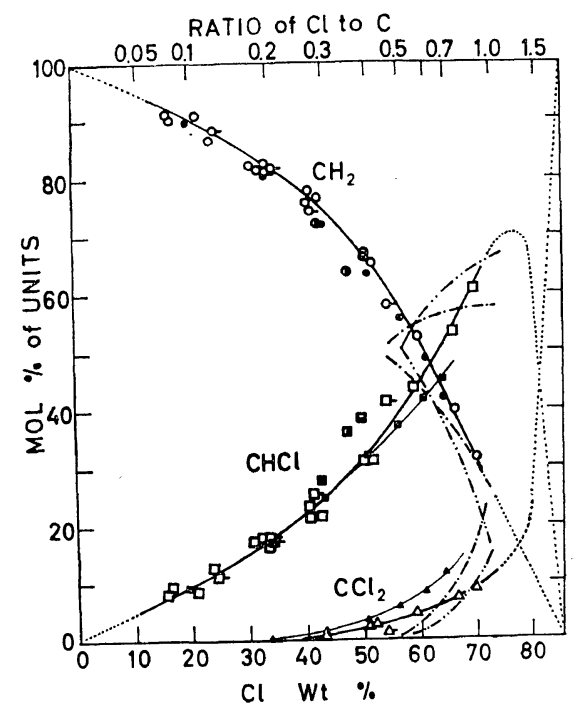

Figure 5. Mole percent of the chemical units in the CPE chain vs. chlorine content: $\bigcirc, \square$, and $\triangle$, suspension CPE; $\bigcirc-, \square-$, and $\triangle$-, solution CPE; $\boldsymbol{0}$, 橉, and $\mathbf{A}$, calculation for a random substitution $^{5}$ and [ HPVC; and $\mathrm{VC}-\mathrm{Et}$ copolymer; - - - and - - - CIPVC and CIPBD, respectively. ${ }^{14}$

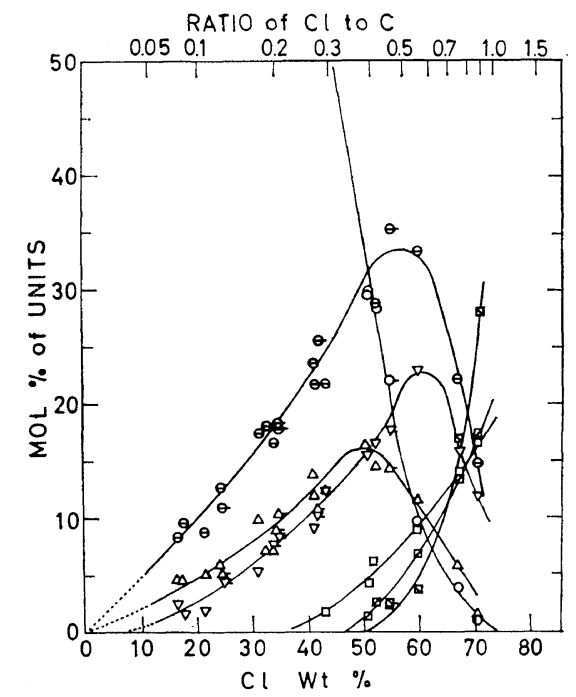

Figure 6. Mole percent of each chemical unit as a content of $\stackrel{*}{\mathrm{E}}$ or $\mathrm{V}^{*} v s$. chlorine content: $(\mathrm{O})$ $\mathrm{a} ;(\triangle) \mathrm{b} ;(\nabla) \mathrm{c} ;(\square) \mathrm{d} ;(\ominus) \mathrm{e} ;(\square) \mathrm{f} ;(\triangle) \mathrm{g}$.

early steps of chlorination.

But in the region of chlorine content $\left(X_{\mathrm{c}}>40\right.$ wt $\%$ ), some selectivity was observed. Geminal-
Table VI. Intrinsic viscosity of CPE

\begin{tabular}{lcc}
\hline Samples & Chlorine content, wt $\%$ & {$[\eta]$} \\
\hline A5FC & 31.1 & 2.10 \\
A6W & 32.7 & 1.56 \\
A7W & 34.0 & 1.72 \\
S2W & 33.8 & 1.55 \\
S3W & 34.7 & 1.95 \\
\hline
\end{tabular}

dichloride units were present only in such sequences as EVEDE or VVEDE, and DEDE units such as vinylidene chloride sequences were ruled out in the CPE chain. The content of $\mathrm{CCl}_{2}$ units therefore was less than that of random substitution, ${ }^{5}$ whereas the content of $\mathrm{CHCl}$ was more than that of random substitution. ${ }^{5}$

Though substitutions by chlorine atoms may be inclined to occur randomly at low chlorine content, the presence of $\mathrm{CCl}_{2}$ units in the CPE chain was observed in the NMR study, after chlorine contents approached ca. $40 \mathrm{wt} \%$ in the solution chlorination (Figure 5). Nevertheless it could not be precisely observed by infrared spectroscopy. ${ }^{2}$

Considering the relative selectivity of the chlorine atom to $n$-paraffins, ${ }^{20}$ it is reasonable to expect that the units of geminal dichloride will be observed at $c a$. $40 \mathrm{wt} \%$ of chlorine.

A comparison of the content of $\mathrm{CCl}_{2}$ units of CPE with that of CIPBD and CIPVC studied by Sobajima, et al. ${ }^{14}$ is shown in Figure 5 . It was found that the relative selectivity of chlorination was affected by the type of parent polymer.

The structure of CPE was believed to be the terpolymer of ethylene, vinylchloride and 1,2dichloroethylene, ${ }^{3}$ and this was recently supported by pyrolysis-gas chromatography. ${ }^{21}$ Though this seemed resonable, the presence of $\mathrm{CCl}_{2}$ units should be also considered as a composition in addition to the above-mentioned compositions at high chlorine content.

As for the effect of the chlorination condition, it was found that the chlorination in solution had a few percent higher $\mathrm{CHCl}$ units and lower $\mathrm{CH}_{2}$ or $\mathrm{CCl}_{2}$ units than those of the suspension method. The S5W sample especially has more VV $\stackrel{*}{V}$ VV units than the value deduced from the character of suspension CPE as depicted in 
Figure 6.

Therefore it may be concluded that the chlorine distribution of CPE depends in part on a chlorination condition, viz., the chlorination in solution prefers a vicinal-dichloride structure rather than a geminal one.

The difference in the chain conformations in solution and in suspension may be one of the reasons for such selectivity.

In the region of chlorine content above 55 wt $\%$, both chlorination methods had a strong tendency to increase the number of vicinaldichloride units rather than the units containing geminal-dichloride units. This tendency was similar to the case of CIPVC which has been reported by many authors.

Tho, et al., ${ }^{16}$ reported an interesting mechanism in order to explain their experimental results as follows

$$
\begin{gathered}
-\mathrm{CHCl}-\mathrm{CHCl}-\mathrm{CH}_{2}-\mathrm{CCl}_{2}- \\
\text { U.V., } \downarrow \quad \mathrm{Cl}_{2} \\
-\mathrm{CHCl}-\mathrm{CHCl}-\mathrm{CH}_{=} \mathrm{CCl}-+\mathrm{HCl} \\
\text { U.V., } \downarrow \quad \mathrm{Cl}_{2} \\
=\mathrm{CHCl}-\mathrm{CHCl}-\mathrm{CHCl}-\mathrm{CHCl}
\end{gathered}
$$

Thus a mechanism is certainly available to explain their result of the change of sequence length as reaction time proceeded preserving constant chlorine content (73 wt \%).

We also consider an analogical mechanism in order to explain our results, viz., the tendency to increase more V $\stackrel{*}{V} V^{*} V$ units than VED units accompanied by the tendency to decrease markedly EV ${ }^{*} E$ or VEV units, as follows

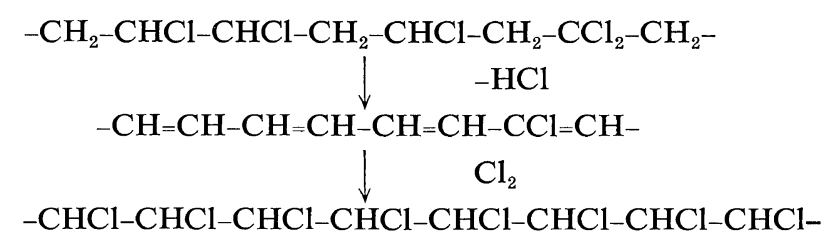

This mechanism is considered the addition reaction of chlorines to the double bond caused by dehydrochlorination, that is, the competition reaction between them. The proposed mechanism is supported by the fact that

(a) chlorine is a powerful homogeneous catalyst for the dehydrochlorination reaction ${ }^{22}$

(b) the rate of addition chlorination to double bonds is greater than that of substitution chlorination of hydrogens on saturated carbons at lower temperature. ${ }^{23}$

The predominance of vicinal-dichloride units will be exaggerated by such addition chlorination and this idea will be also adopted to explain the structure in the CIPVC chain.

\section{Sequence Length Distribution of Methylene}

We have described the distribution of chlorinated units as a content of the triad or the pentad sequences and the selectivity of chlorination in previous sections. Let us now consider the sequence length of unsubstituted methylenes in order to make the distribution of chlorine atoms much clearer from another point of view.

(i) Contents of the Various Methylene Sequences Molar percent, $P(N)$, which means the expecta- tion of finding the asterisked methylenes in a block of $N$ unsubstituted methylenes which are begun with $\mathrm{V}$ or $\mathrm{D}$ and terminated by $\mathrm{V}$ or $\mathrm{D}$ such as,

$-(\mathrm{CHCl})$ or $-\left(\mathrm{CCl}_{2}\right)-\left(\mathrm{CH}_{2}\right)_{N}-(\mathrm{CHCl})-$ or $-\left(\mathrm{CCl}_{2}\right)-$ can be readily given as follows

$$
\begin{aligned}
& P(1)=c+d \\
& P(2)=b \\
& P(3)=a_{3} \\
& P(4)=a_{2} \\
& P(N \geqq 5)=a_{1}
\end{aligned}
$$

The results of the above equations are shown in Figure 7.

$P(N)$ can be also calculated by the statistical method which has been skilfully treated by Frensdorff and Ekiner ${ }^{5}$ for general substituted polymers. From their results $\boldsymbol{P}(N)$ is as follows

$$
P(N)=100 \pi_{0}\left(1-\Gamma_{00}\right)^{2} N \Gamma_{00}{ }^{(N-1)}
$$

Eq 34 was given the same meaning by them as mentioned above and therefore this equation is satisfactory for use in respect of the CPE chain. 
High-Resolution NMR Study of Chlorinated Polyethylenes

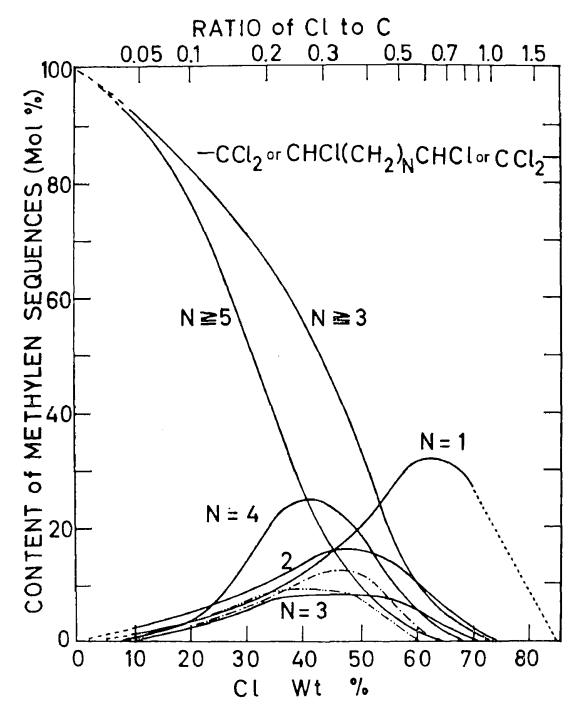

Figure 7. Mole percent of the each sequence length, $-\left(\mathrm{CH}_{2}\right)_{N}-$ as a content of $\underset{\mathrm{E}}{\mathrm{*}}$ vs. chlorine content: - $\longrightarrow$, the result from eq $29-33$; - - and $-\cdots, P(3)$ and $P(4)$ respectively from eq 38 .

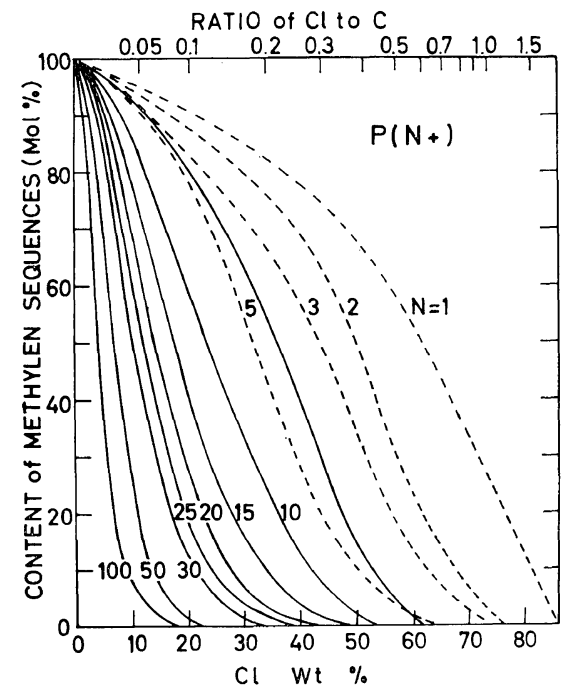

Figure 8. Distribution of methylene-sequence length $P(N+)$ as a function of chlorine content: ----, experimental; — $\longrightarrow$, from eq 39.

Table VII. The output value of $P(N+)$ from eq 39 (mol \%)

\begin{tabular}{cccccccccc}
\hline Cl wt $\%$ & $P(5+)$ & $P(10+)$ & $P(15+)$ & $P(20+)$ & $P(25+)$ & $P(30+)$ & $P(40+)$ & $P(50+)$ & $P(100+)$ \\
\hline 2.5 & 98.7 & 98.4 & 97.9 & 97.1 & 96.3 & 95.2 & 92.8 & 90.0 & 72.7 \\
5.0 & 97.4 & 95.9 & 93.7 & 90.9 & 87.6 & 84.0 & 76.3 & 68.3 & 34.4 \\
7.5 & 95.5 & 92.2 & 87.4 & 81.7 & 75.6 & 69.3 & 56.9 & 45.8 & 12.7 \\
10.0 & 93.2 & 86.7 & 78.1 & 68.8 & 59.6 & 50.9 & 36.0 & 24.8 & 3.0 \\
15.0 & 87.6 & 74.0 & 58.9 & 45.1 & 33.6 & 24.6 & 12.6 & 6.2 & 1.3 \\
20.0 & 80.7 & 59.8 & 40.7 & 26.3 & 16.4 & 10.0 & 3.5 & 1.2 & 0.0 \\
30.0 & 62.9 & 32.1 & 14.3 & 5.9 & 2.3 & 0.9 & 0.1 & 0.0 & 0.0 \\
40.0 & 41.1 & 11.5 & 2.7 & 0.6 & 0.1 & 0.0 & 0.0 & 0.0 & 0.0 \\
50.0 & 12.2 & 0.7 & 0.0 & 0.0 & 0.0 & 0.0 & 0.0 & 0.0 & 0.0 \\
60.0 & 0.3 & 0.0 & 0.0 & 0.0 & 0.0 & 0.0 & 0.0 & 0.0 & 0.0 \\
70.0 & 0.0 & 0.0 & 0.0 & 0.0 & 0.0 & 0.0 & 0.0 & 0.0 & 0.0
\end{tabular}

a The input data were tabulated in Table VIII.

$P(N+)$, which means summation of $P(N)$ for the number of larger than, or equal to $N$, are defined as

$$
\begin{aligned}
P(N+) & =100 \sum_{n=N}^{\infty} P(n) \\
& =100 \pi_{0}\left[N\left(1-\Gamma_{00}\right)+\Gamma_{00}\right] \Gamma_{00}{ }^{(N-1)}
\end{aligned}
$$

where $\pi_{i}(i=0,1$ and 2$)$ is the unit probability that the $(n-1)$ st unit has $i$ chlorine atoms and $\Gamma_{i j}$ is the conditional probability that the $n$-th repeat unit has $j$ chlorine atoms and the $(n-1)$ st unit has $i$ chlorine atoms, that is, $\pi_{0}$ is the unit probability of finding YEZ and $\Gamma_{00}$ is the diad probability of finding $\mathrm{YEE}^{*} \mathrm{E}(\mathrm{Y}, \mathrm{Z}=\mathrm{E}, \mathrm{V}$ or D) in the CPE chain.

Hence,

$$
\begin{aligned}
\Gamma_{00} & =0.01(a+b)=A+B \\
\pi_{0} & =0.01 E_{1}
\end{aligned}
$$

where, $A=0.01 a$ and $B=0.01 b$. Inserting eq 36 and 37 into eq 34 and $35, P(N)$ or $P(N+)$ can be rewritten as

$$
P(N)=E_{1}[1-(A+B)]^{2} N(A+B)^{N-1}
$$




$$
\begin{aligned}
P(N+)= & E_{1}[N(1-A-B) \\
& +(A+B)](A+B)^{N-1}
\end{aligned}
$$

Computed results are listed in Table VII and depicted in Figure 8.

(ii) Mean-Sequence Number of Methylene Sequences

Supposing that the total number of methylene units $\left(E_{1}\right)$ are divided into equal block length by chemical units such as $\mathrm{CHCl}$ or $\mathrm{CCl}_{2}$, the mean sequence number $(\bar{N})$ can be calculated arithmetically.

$$
\bar{N}=E_{1} /\left(V_{\mathrm{e}}+D_{\mathrm{e}}+1\right)
$$

where, $V_{\mathrm{e}}$ and $D_{\mathrm{e}}$ means effective number of $\mathrm{CHCl}$ and $\mathrm{CCl}_{2}$ to separate unsubstituted methylenes.

In estimating $V_{\mathrm{e}}$, it is assumed that $\mathrm{V}$ in the $V V^{*} V$ sequence does not contribute to $V_{\mathrm{e}}$ and $\mathrm{V}^{*}$ in the EVV triad contributes by half to $V_{\mathrm{e}}$, while $\stackrel{*}{V}$ in the EVE triad contributes completely to $V_{\mathrm{e}}$.

$$
\text { Hence, } \quad V_{\mathrm{e}}=e+(f+g / 5) / 2
$$

$D_{\text {e }}$ was estimated from the following relation

$$
D_{\mathrm{e}}=D_{1}
$$

because, in our results, $\mathrm{CCl}_{2}$ units existed only in the unit of EDE sequence.

The most probable number $\langle N\rangle$ of methylene sequences in the case of uniform distribution of chlorine atoms along the chain can also be calculated from the chlorine content $\left(x_{\mathrm{c}}\right)$ on the assumption that neither geminal-dichloride nor vicinal-dichloride structures exist. That is

$$
\langle N\rangle=\left(35.5-48.5 x_{\mathrm{c}}\right) / 14.0 x_{\mathrm{c}}
$$

where $x_{\mathrm{c}}$ is equal to the chlorine weight fraction.

Frensdorff and Ekiner obtained mean length $\bar{n}$ and the most probable length $\langle n\rangle$ as follows

$$
\begin{aligned}
\bar{n} & =\left(1-\Gamma_{00}\right)^{-1} \\
\langle n\rangle & =-\left(\ln \Gamma_{00}\right)^{-1}
\end{aligned}
$$

The numerical values of $\bar{n}$ and $\langle n\rangle$ are in close agreement with those of $\bar{N}$ and $\langle N\rangle$ respectively, as shown in Figure 9.

As for the sequence number larger than five, which cannot be determined directly from NMR spectroscopy, the average-sequence number $(\bar{L}$, $\bar{l})$ can be obtained approximately from the following equations

$$
\begin{aligned}
\bar{L}= & \{\bar{N}(a+b+c+d) \\
& \left.-\left[(c+d)+2 b+3 a_{3}+4 a_{2}\right]\right\} / a_{1} \\
\bar{l}= & \left\{\left[\sum_{N=5}^{99} N P(N)\right]+100 P(100+)\right\} / \\
& \left\{\left[\sum_{N=5}^{99} P(N)\right]+P(100+)\right\}
\end{aligned}
$$

\begin{tabular}{|c|c|c|c|c|c|c|c|}
\hline \multirow{2}{*}{$\mathrm{Cl}$ wt $\%$} & \multicolumn{3}{|c|}{ Input data } & \multirow{2}{*}{$\begin{array}{c}\text { Eq } 44 \\
\bar{n}\end{array}$} & \multirow{2}{*}{$\begin{array}{c}\text { Eq } 45 \\
\langle n\rangle\end{array}$} & \multirow{2}{*}{$\begin{array}{l}\text { Eq } 43 \\
\langle N\rangle\end{array}$} & \multirow{2}{*}{$\begin{array}{c}\mathrm{Eq} 47 \\
\bar{l}\end{array}$} \\
\hline & $0.01 E_{1}$ & $A$ & $B$ & & & & \\
\hline 2.5 & 0.988 & 0.985 & 0.005 & 100.5 & 99.5 & 98.0 & 89.7 \\
\hline 5.0 & 0.978 & 0.968 & 0.010 & 45.5 & 45.0 & 47.3 & 69.9 \\
\hline 7.5 & 0.966 & 0.950 & 0.015 & 28.6 & 28.1 & 30.4 & 52.5 \\
\hline 10.0 & 0.955 & 0.928 & 0.020 & 19.2 & 18.7 & 21.9 & 37.7 \\
\hline 15.0 & 0.933 & 0.880 & 0.035 & 11.8 & 11.3 & 13.4 & 23.8 \\
\hline 20.0 & 0.909 & 0.830 & 0.050 & 8.3 & 7.8 & 9.2 & 17.2 \\
\hline 30.0 & 0.853 & 0.712 & 0.088 & 5.0 & 4.5 & 5.0 & 11.2 \\
\hline 40.0 & 0.785 & 0.565 & 0.133 & 3.3 & 2.8 & 2.9 & 8.3 \\
\hline 50.0 & 0.673 & 0.330 & 0.165 & 2.0 & 1.4 & 1.6 & 6.3 \\
\hline 60.0 & 0.500 & 0.085 & 0.105 & 1.2 & 0.6 & 0.8 & 5.2 \\
\hline 70.0 & 0.297 & 0.010 & 0.023 & 1.0 & 0.3 & 0.2 & 0.0 \\
\hline
\end{tabular}

The chemical shift at $8.65 \mathrm{ppm}$ would arise from the protons in methylene sequences of the average sequence number such as $\bar{L}$ or $\bar{l}$, though considerable difference between $\bar{L}$ and $\bar{l}$ was observed.

In these treatments, the input data listed in Table VIII to solve eq $38,39,44,45$, and 47 with a computer were estimated from Figures 5 and 7 . The calculated results are summarized

Table VIII. Mean length and most probable length of methylene sequence 
Table IX. Mean-sequence length of methylene from eq 40 or 46

\begin{tabular}{lrrrr}
\hline Sample & $V_{\mathrm{e}}$ & \multicolumn{1}{c}{$D_{\mathrm{e}}$} & \multicolumn{1}{c}{$N$} & \multicolumn{1}{c}{$L$} \\
\hline A1FE & 8.4 & 0.0 & 9.8 & 10.8 \\
A2FE & 9.8 & 0.0 & 8.4 & 9.3 \\
A3FE & 8.8 & 0.0 & 9.3 & 10.3 \\
A4W & 12.8 & 0.0 & 6.3 & 7.6 \\
A5FC & 17.5 & 0.0 & 4.5 & 6.0 \\
A6W & 18.1 & 0.0 & 4.3 & 5.6 \\
A7W & 16.6 & 0.0 & 4.7 & 6.3 \\
A8FC & 23.7 & 0.0 & 3.1 & - \\
A9W & 21.8 & 0.0 & 3.4 & 5.2 \\
A10W & 21.9 & 1.0 & 3.2 & - \\
A11FE & 30.7 & 2.2 & 1.9 & - \\
A12W & 30.1 & 3.0 & 1.9 & - \\
A13FE & 37.4 & 4.3 & 1.2 & - \\
A14FE & 32.7 & 7.1 & 1.0 & - \\
A15FE & 29.1 & 8.4 & 0.8 & - \\
S1W & 11.2 & 0.0 & 7.3 & 9.6 \\
S2W & 18.4 & 0.0 & 4.2 & 6.2 \\
S3W & 17.9 & 0.0 & 4.3 & 6.4 \\
S4W & 25.7 & 0.0 & 2.8 & - \\
S5W & 37.6 & 1.4 & 1.4 & - \\
HPVC1 & 28.0 & 0.0 & 2.5 & - \\
HPVC2 & 36.2 & 0.0 & 1.7 & - \\
VC-Et & 38.9 & 0.0 & 1.5 & - \\
\hline a -1 less & than five. & & & \\
\hline
\end{tabular}

in Tables VIII and IX.

$P(N),(N=1,2,3,4)$ depicted in Figure 7 as a function of chlorine content have a maximum point in the vicinity of chlorine to carbon ratio $(1 /(N+1))$. This fact appears to be quite reasonable considering that polyethylene is rather randomly substituted by chlorine atoms.

There is, however, the question of whether or not the values of $\alpha$ and $\beta$ in eq 20,21, and 22 are really adequate.

It was shown in Figure 8 that $P(N \geqq 5)$ from eq 33 was less than $P(5+)$ from eq 39 , and the difference between $\bar{L}$ and $\bar{l}$ was great as shown in Tables VIII and IX .

This fact led to the comment that the contribution of $-\left(\mathrm{CH}_{2}^{*}\right)_{N^{-}}(N \geqq 5)$ to $-\left(\mathrm{CH}_{2}\right)_{4^{-}}$or $-\left(\mathrm{CH}_{2}^{*}\right)_{3}$ - could not be ignored in estimating the degree of overlapping peaks, and the values of $\alpha$ and $\beta$ estimated from the model compounds were not adequate for CPE.

Although the values of $\alpha$ and $\beta$ could not be determined precisely in this paper, it can be pointed out from an inspection of the result in Figures 7 and 8 that those values are dependent at least on the chlorine content. If eq 38 is thoroughly accepted, those values will be determined using eq 38. (Calculated results of $P(3)$ and $P(4)$ from eq 38 were also shown in Figure 7.)

The resultant values of $\alpha$ and $\beta$ can be calculated repeatedly from a model sequence of $\mathrm{CPE}$ which is formulated with the given values of $\alpha$ and $\beta$, and the triad probability. Therefore, after the resultant values coincide self-consistently with the given values, the most probable values of $\alpha$ and $\beta$ will be also determined. Further work is being carried out to resolve this problem with the aid of a computer.

Setting aside this question, a substantial tendency for chlorine distribution along the CPE chain has been shown and some structure sensitive properties will be explained from the results in Figure 8.

For instance, inspection of the result shown in Figure 8 reveals that $P(30+)$, which may be considered a component of the least crystallizable methylene-sequence length, is speedily reduced and disappears at $c a .30 \mathrm{wt} \%$ of chlorine.

Thus the remarkable decrease in crystallinity $\left(X_{\mathrm{cr}}\right)$ as chlorination proceeds $\left(X_{\mathrm{cr}}=59 \mathrm{wt} \%\right.$ at $19 \mathrm{Cl}$ wt $\%$ and $X_{\mathrm{cr}}=45 \mathrm{wt} \%$ at $24 \mathrm{Cl}$ wt $\%$ by $X$-ray) should be a reflection of the remarkable decrease of contents of the long methylene sequences as shown in Figure 8.

The same melting temperature for $\mathrm{CPE}$ as that of the original PE is often observed in a whole polymer even at $40-50 \mathrm{wt} \%$ of chlorine by DSC or DTA measurement. It is suggested from the results in Figure 8 that such an observation cannot be due to the existence of the crystallizable long methylene sequences along polymer chains but to the residual crystals of unsubstituted PE arising from the distribution of "chlorine-content" in the whole polymer, and this is a notable point.

The distribution of methylene sequences or chlorine atoms in the CPE chain is characterized discriminately by the mean-sequence length as shown in Figure 9.

The mean-sequence length of HPVC or VCEt copolymer was in close agreement with the most probable length according to their chlo- 


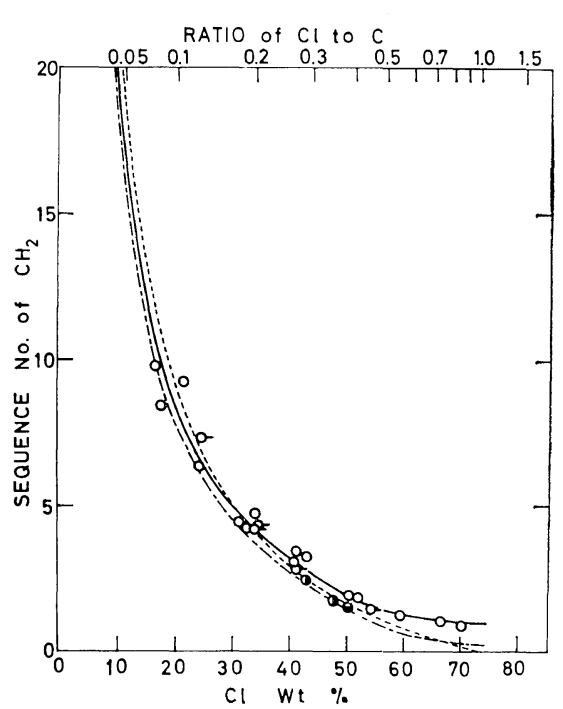

Figure 9. Sequence number of methylene as a function of chlorine content: $\bigcirc, \bigcirc-, \boldsymbol{O}$, and $\ominus$, mean-sequence length of suspension CPE, solution CPE, HPVC, and VC-Et copolymer respectively from eq 40 ; ------, most probable length $\langle N\rangle$ from eq $43 ;-$, mean-sequence length $\bar{n}$ from eq 44 ; --- , most probable length $\langle n\rangle$ from eq 45 .

rine contents, whereas that of CPE was larger than that of HPVC or VC-Et copolymer owing to the presence of $\mathrm{CCl}_{2}$ units or vicinal-dichloride units.

\section{CONCLUDING REMARKS}

In summary, NMR spectroscopy has made it possible to resolve and identify the triad and pentad units of CPE.

Quantitative results of various triads and the methylene-sequence distribution were obtained to clarify the chlorine distribution along the polymer chain with sufficient accuracy.

The mean-sequence number of methylene units has been shown to be in close agreement with that obtained by means of the statistical treatment by Frensdorff, et al.

Although the mean-sequence number is drastically decreased with the introduction of chlorines, it remains at about unity even in the region of chlorine content $60-70 \mathrm{wt} \%$.

The distribution of chlorines in the CPE chain can be considered as a rather statistically random distribution at low chlorine content. However, neither vinylidene chloride sequences such as $\left(-\mathrm{CH}_{2}-\mathrm{CCl}_{2}-\mathrm{CH}_{2}-\mathrm{CCl}_{2}-\right)$ nor chemical units such as $\left(-\mathrm{CH}_{2}-\mathrm{CCl}_{2}-\mathrm{CH}_{2}-\mathrm{CH}_{2}-\right)$ have been observed, and geminal-dichloride units were observed only in such units as $\left(-\mathrm{CH}_{2}-\mathrm{CCl}_{2}-\mathrm{CH}_{2}-\mathrm{CHCl}-\right)$ at high chlorine contents.

The structure of CPE was found to be affected slightly by the chlorination condition, but scarcely affected at all by the molecular weight of the parent polymer.

It may be pointed out that firstly, the structure of CPE is discriminative from that of HPVC or VC-Et copolymer and particularly from that of PVC. Secondly, the definite line should be drawn between the chlorine distribution along the polymer chain and the chlorine-content distribution in the whole polymer.

Acknowledgments. The authors are indebted to Dr. Y. Uchida of Tokyo University for providing (vinyl chloride)-ethylene copolymer and for the help and information he made available.

They are grateful to Mr. N. Tanaka of this laboratory for his valuable comments during the course of this work, and to Mr. K. Kosaka who kindly carried out the NMR measurements.

They also wish to acknowledge the contribution by Mr. Y. Koike, who carried out the computer calculations.

Acknowledgements. The authors wish to express their thanks to Miss M. Kashimura for typing the final manuscript.

\section{REFERENCES}

1. H. W. Thompson and P. Torkington, Trans, Faraday Soc., 41, 246 (1945).

2. K. Nambu, J. Appl. Polym. Sci., 4, 69 (1960).

3. H. J. Oswald and E. T. Kubu, SPE Trans., July, 1963 p 168.

4. T. Saito, Preprint, SPSJ 16 th Symposium on Macromolecules, at Fukuoka, 1967, p 110 IID08.

5. H. K. Frensdorff and O. Ekiner, J. Polym. Sci., Part A-2, 5, 1157 (1967).

6. R. Chujo, S. Satoh, and Nagai, J. Polym. Sci., Part A, 2, 895 (1964).

7. J. L. McClanahan and S. A. Previtera, J. Polym. Sci., Part A, 3, 3919 (1965).

8. U. Johnsen, Kolloid-Z. Z. Polym., 210, 1 (1966). 
9. S. Enomoto and S. Satoh, Kolloid-Z. Z. Polym., 219, 12 (1967).

10. Y. Yamashita, K. Ito, H. Ishii, and M. Kai, Macromolecules, 1, 529 (1968).

11. A. Misono, Y. Uchida, and K. Yamada, Bull. Chem. Soc. Japan, 39, 2458 (1966); ibid., 40, 2366 (1967); ibid., 412995 (1968); Private Communication (submitted to Bull. Chem. Soc. Japan).

12. J. Schaefer, J. Phys., Chem., 70, 1975 (1966).

13. C. E. Wilkes, J. C. Westfahl, and R. H. Backderf, J. Polym. Sci., Part A-1, 7, 23 (1969).

14. S. Sobajima, N. Takagi, and H. Watase, $J$. Polym. Sci., Part A-2, 6, 223 (1968).

15. J. Petersen and Rånby, Makromol. Chem., 102, 83 (1967).

16. Pham-Quang-Tho and P. Berticat, Eur. Polym. J., 4, 265 (1968).

17. G. Svegliado and F. Z. Grandi, J. Appl. Polym. Sci., 13, 1113 (1969).
18. J. W. Emsley, J. Feeney, and L. H. Sutcliffe, "High Resolution Nuclear Magnetic Resonance Spectroscopy,"' Pergamon Press, Oxford, 1966, p 838.

19. J. D. Cotman, Jr., J. Amer. Chem. Soc., 77, 2790 (1955).

20. N. Colebourne and E. S. Stern, J. Chem. Soc., 1965 June, p 3599.

21. S. Tsuge, T. Okumoto, and T. Takeuchi, Macromolecules, 2, 200 (1969).

22. P. H. Groggins, "Unit Processes in Organic Synthesis," McGraw-Hil Book Co., Inc., New York, N.Y., 1958, p 213.

23. P. H. Groggins, ibid., 1958, p 221.

24. T. Saito, unpublished data.

25. U. Johnsen, J. Polym. Sci., 54, S6 (1961); R. Chujo, S. Satoh, T. Ozeki, and E. Nagai, J. Polym. Sci., 61, S12 (1962); W. C. Tincher, J. Polym. Sci., 62, S148 (1962). 